\title{
Self-Medication in Pregnancy and Associated Psychopathological Symptoms of Antenatal Nigerian Women
}

\author{
Ebenezer Olutope Akinnawo', Ibukunoluwa Busayo Bello',

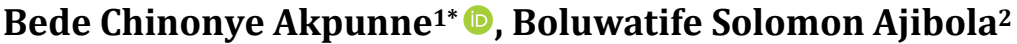 \\ ${ }^{1}$ Department of Behavioural Studies, Faculty of Social Sciences, Redeemer's University, Ede, Osun State, Nigeria \\ ${ }^{2}$ Department of International Development, London School of Economics and Political Science (LSE), London, UK \\ Email: ^akpunneb@run.edu.ng
}

How to cite this paper: Akinnawo, E. O., Bello, I. B., Akpunne, B. C., \& Ajibola, B. S. (2020). Self-Medication in Pregnancy and Associated Psychopathological Symptoms of Antenatal Nigerian Women. Psychology, 11, 2039-2054.

https://doi.org/10.4236/psych.2020.1112127

Received: November 7, 2020

Accepted: December 26, 2020

Published: December 29, 2020

Copyright $\odot 2020$ by author(s) and Scientific Research Publishing Inc. This work is licensed under the Creative Commons Attribution International License (CC BY 4.0).

http://creativecommons.org/licenses/by/4.0/

\begin{abstract}
The physical and psychological health challenges of Self-Medication (SM) for a pregnant woman and the unborn child spotlights it as an emergency. This unwraps a gap in epidemiological studies on SM and associated psychopathological symptoms among Nigerian pregnant women. This study examines the predictive influence of self-medication with Over The Counter (OTC) drugs on manifested psychopathological symptoms among pregnant women attending antenatal clinic in State Specialist Hospital, Osogbo, Osun State, southwestern Nigeria. Purposively selected 277 pregnant women $(\bar{x}$ age $=$ 29.33; $\mathrm{SD}=4.77)$ participated in the study. The participants responded to the Substance Abuse Prevalence Inventory, Self-Medication Test (SMT), and Awaritefe Psychological Index (API). Findings reveal a low prevalence of psychoactive drug use (2.8\%) and a high prevalence of (OTC) drug self-medication (31.4\%) and psychopathological symptoms (34.7\%). Self-medication with OTC drugs independently and significantly predicted severities of insomnia $(\beta=.178, p=.001)$, intellect disorder $(\beta=.244, p=.000)$, heat disorder $(\beta=.109, p=.046)$, mood disorder $(\beta=.188, p=.001)$, head region disorder $(\beta=.162, p=.003)$, alimentary tract disorder $(\beta=.118, p=.030)$, general somatic disorder $(\beta=.244, p=.000)$, and general psychopathology ( $\beta$ $=.229, p=.000)$. The study reports a high prevalence of psychopathological symptoms among the Nigerian sample and concludes that the SM of OTC drugs is a significant predictor of the severity of the symptoms of psychopathology among pregnant women.
\end{abstract}

\section{Keywords}

Self-Medication, Over-the-Counter Drugs, Psychopathological Symptoms, 
Pregnant Women, Nigeria

\section{Introduction}

Self-medication (SM) is considered a significant concern across the globe (Jalilian, Hazavehei, Vahidinia et al., 2017; World Health Organization (WHO, 1998). Studies reveal that only around $10 \%-30 \%$ of symptoms experienced by individuals are brought to a physician's attention and that, in most cases, most symptoms are either tolerated or self-medicated (Abula \& Worku, 2001). SM is the selection and use of medicines by individuals to treat self-recognized illnesses or symptoms (WHO, 1998). SM is not limited to orthodox medications; it also includes alternative medicine (herbal drugs), commonly seen in African settings (Hughes, McElnay, \& Fleming, 2001; Kamat \& Nichter, 1998).

SM is fast attracting significant attention in the health care policies of both developed and developing countries (Karimy, Rezaee-Momtaz, Tavousi et al., 2019; Eticha \& Mesfin, 2014; Angamo \& Wabe, 2012; Chang \& Trivedi, 2003; Sleath, Rubin, Campbell et al., 2001). Global health concerns about pregnant women's medication predate the $21^{\text {st }}$ Century (Gebreegziabher, Berhe, Gutema, \& Kabtyimer, 2012; Wondesen, Satessa, \& Gelaw, 2016), its abuse has lingered in the developing world (Gbagbo \& Nkrumah, 2020).

In most developing countries such as Nigeria, about $60 \%-80 \%$ of health-related problems are treated using self-medication (Mossa, Wabe, \& Angamo, 2012; Gutema, Gadisa, Kidanemariam et al., 2011; Khan, 2011). Factors responsible for the rise in SM across the globe include socioeconomic factors, lifestyle, ready access to drugs, increased potential to manage certain illnesses through self-care, and greater availability of medicinal products (Avalew, 2017). Other factors include the wrong perception of the severity of illness, previous pleasant experiences with SM, belief in self-care, and non-availability of physicians (Garofalo, Di Giuseppe, \& Angelillo, 2015; Suleman, Ketsela, \& Mekonnen, 2009; Afolabi, 2009; Shankar, Partha, \& Shenoy, 2002). To lend more evidence to this, a cross-sectional study (Schwarz, Buschel, \& Kirch, 2008) on 384 pregnant women conducted in Iran, comparing the prevalence of SM before and during pregnancy, revealed that SM was prevalent among $63.9 \%$ of women before pregnancy and $43.5 \%$ during pregnancy.

Studies show that when properly practiced, SM can positively impact health care systems (Eticha \& Mesfin, 2014), through decreased health care costs, less burden of care. Additional resources to manage more severe ailments (Mihretie, 2014; Almasdy \& Sharrif, 2011).

Despite its positive impacts, the adverse effects of SM include risks of misdiagnosis, overdose, incorrect duration of use, and adverse drug reactions (Hughes, McElnay, \& Fleming, 2001; Ruiz, 2007). Other adverse impacts include drug abuse, waste of resources, increased risk of unwanted effects, and prolonged suf- 
fering as a result of a potential delay in treating severe medical conditions, masking of symptoms of severe conditions, and increased poly-pharmacy and interaction with other regularly used medications (Angamo \& Wabe, 2012; Buck, 2007).

The increasing effects of SM on pregnant women and children have further exposed government action gaps needed to drive control. The need to increase awareness about the importance of responsible self-medication has invited regulatory support, to which the government is central, as acknowledged (Bennadi, 2014). Thus, with the institution of the National Agency for Food and Drug Administration and Control (NAFDAC) in Nigeria, the government should be able to match its policy might with adequate control. This said, while the institutionalization and enforcement of controls are made evident on the one hand, gaps in knowledge on other connected issues, mainly as they concern the effects of self-medicating OTC drugs, should also be prioritized on the other.

There is a knowledge gap on the epidemiology of SM during pregnancy and associated psychopathological symptoms in Nigerian studies. The history of pregnancy-related fatalities is observable in Nigeria. Figure 1 shows five countries with the highest number of global maternal deaths in 2015, with Nigeria recording 58,000 deaths.

However, in 2016, a statistic reports Nigeria to have dropped to the secondhighest country with maternal deaths in the world (Ameh, Adeleye, Kabiru et al., 2016).

Generally, pregnant women use prescription and non-prescribed Over-TheCounter (OTC) drugs (Karimy, Rezaee-Momtaz, Tavousi et al., 2019: Lacroix, Damase-Michel, Lapeyre-Mestre et al., 2000). However, pregnant women are typically not included in clinical trials because it may be harmful to the mother and her developing fetus (Mitchell, 2002; Wood, Koren, Pastuszak et al., 1998).

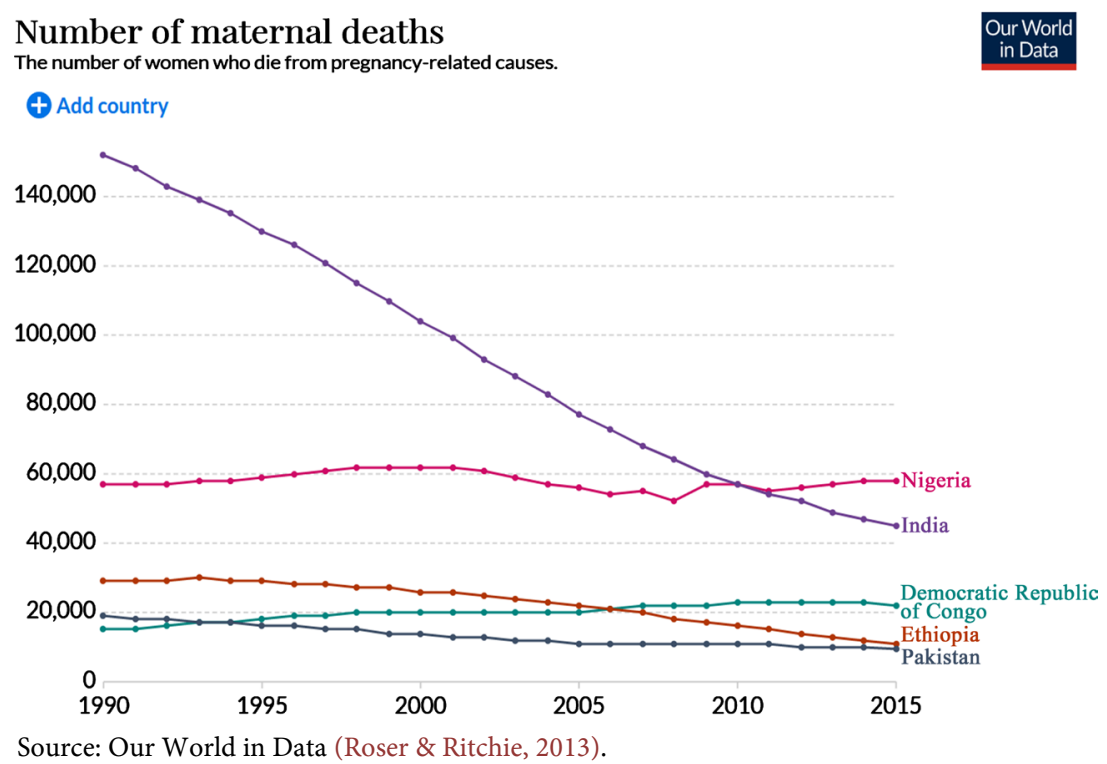

Figure 1. Chart of the number of pregnancy-related maternal deaths in Nigeria. 
The only available information on drug effects during pregnancy is derived from preclinical studies that involve animals, which cannot be directly generalized to pregnant women (Czeizel, Gidai, Petik et al., 2008; Ward, Sevene, Hastings et al., 2007). Literature gives insight into the possibility of toxic effects of drugs on the fetus and the pregnant woman (Ward, Sevene, Hastings et al., 2007; Fantel, Shepard, Newell-Morris et al., 1977). Most drugs used in clinical practice have limited information on the safety in pregnancy and are often not recommended for use among pregnant women (Dellicour, ter Kuile, \& Stergachis, 2008; Ward, Sevene, Hastings et al., 2007).

Studies reveal that SM with OTC drugs and the use of illicit substances during pregnancy may result in hormonal imbalance, low birth weight, premature labour, placenta abruption, fetal death, and maternal death (Leung, Saini, \& Ritchie, 2018; Ravindu \& Avinash, 2018).

SM and its associated influence on the psychological health of Nigerian pregnant women are yet to receive adequate research attention. To fill this knowledge gap, we hypothesize that the Self-Medication of OTC drugs will significantly predict psychopathological symptoms among pregnant Nigerian women attending an antenatal clinic.

\section{Materials and Methods}

\subsection{Research Design}

This study adopted a cross-sectional hospital-based exploratory survey research method.

\subsection{Study Area}

The Osun State government-owned Specialist Hospital located in Asubiaro, Osogbo metropolis in Osun State, southwestern Nigeria, was used for this study. Osogbo, Osun State was selected for this study because of its reported high average attendance at antenatal clinics compared to the National average (OlugbengaBello, Adebimpe, Osundina, \& Abdulsalam, 2013). The Antenatal Unit of the State Specialist Hospital was the specific location of this study. Participants were sampled during clinic hours, primarily from 8:00 am to 04:00 pm.

\subsection{Participants}

The study employed a purposive sampling technique in selecting 277 participants for this study. All pregnant women attending antenatal clinic sessions at the State Specialist Hospital, Asubiaro, Osogbo, Osun State, as at the time of the study, were eligible as study participants. Data was gotten from respondents on four clinic days weekly (Mondays, Tuesdays, Wednesdays, and Thursdays) between April and June 2018. Questionnaires were self-administered at the antenatal clinic and retrieved on completion. Participants were also implored to review their responses in case there was any missing item. A modification of the Cochran formula for sample size determination in smaller populations was used 
to determine the sample size, and 277 participants were employed in the study.

\subsection{Participants' Inclusion-Exclusion Criteria}

Only pregnant women registered with and attending antenatal clinics at the State Specialist Hospital, Asubiaro, Osogbo, Osun State were sampled. Also, of the pregnant women, only those in good physical condition (self-reported) who were willing to spend about 8 minutes for the study were sampled.

These inclusion criteria provided this study with a valid research outcome by minimizing the possibility of responses that could originate from non-pregnant women, pregnant women experiencing ill health, and those who expressed a lack of time to attempt the battery of psychological tests carefully. Furthermore, these inclusion criteria facilitated easier and more effective data collection and helped to ensure that all prospective respondents were adequately informed on the purpose of the study, thereby fostering motivation and true response.

\subsection{Research Instruments}

The study made use of a battery of three psychological research instruments for the study, namely the Awaritefe Psychological Index (API), Substance Abuse Prevalence Inventory (SAPI), and Self-Medication Test (SMT).

Awaritefe (Awaritefe, 1982) developed the Awaritefe Psychological Index (API). The API (Form X) is used to measure general psychopathology. The API is a 76-item scale divided into seven subscales (sleep disorder, intellect disorder, heat disorder, mood disorder, head region disorder, alimentary tract disorder, and general somatic disorders). The higher a respondent scores on the test, the lower the level of the participant's psychopathology. The instrument also has a split-half reliability coefficient of .85 (Akinnawo \& Oforwe, 2012).

The study employed the Substance Abuse Prevalence Inventory (SAPI) developed by Omoluabi (Omoluabi, 1995) to collect data on the respondent's drug use. SAPI is a 19-item scale that has two subsets that are comprised of Column A and Column B to measure the frequency and quantity of consumption/misuse of various psychoactive drugs within thirty days. The higher the score on column $A$, the higher the frequency of substance use, and the higher the scores on column B, the more the quantity consumed. The total scores on the test reveal a respondent's substance use. The reliability coefficient of the scale using test-retest within three weeks interval shows that for frequency $\mathrm{r}=.51 p<.05$ and for quantity $r=.76$. This reliability coefficient is sufficient for the scale to be used as an assessment instrument. SAPI was correlated with the Eysenck Personality questionnaire to estimate the concurrent validity. The result shows that the scale possesses a good concurrent validity coefficient of $r=.55$ for extraversion and $r$ $=.99$ for neuroticism (Omoluabi, 1995).

The Self-medication Test (SMT) is a self-constructed psychological test that contains twelve classes of commonly abused over-the-counter drugs during pregnancy. These over-the-counter drugs include folic acid, Vitamin B supple- 
ments, pain relief tablets, blood tonic, slimming pills, teas, sleeping pills, Flagyl, antidiarrheal, antibiotics, Omega-3 supplements, calcium supplements, and herbs. Respondents are to indicate their frequency of use of these drugs since they have been pregnant. Possible responses range from "Never" to "Always" on a 5-point Likert scale. The higher the score obtained, the higher the frequency of usage.

\section{Results}

\subsection{Socio-Demographic Data of Respondents}

The observed socio-demographic profile shows that all the respondents are aged between 19 - 43 years old, with a mean age of 29.33 years. The age range correlates with the national reproductive age group, which is 18 - 49 years. Additionally, the data on the age of the respondents is dynamic and accommodates adolescents, young adults, adults, and older adults. Furthermore, $172(62.1 \%)$ of the respondents are Christian, $102(36.6 \%)$ are Muslims, and African Traditional Religion faithful are 3 (1.1\%); this gives an insight into the two predominant religions in the study area. A total of 257 (92.8\%) of the respondents are Yoruba, 4 (1.4\%) are Igbos, 8 (2.9\%) are Hausas, and $8(2.9 \%)$ are from other ethnic groups in Nigeria; the variation in ethnicity is a result of the dense population of Yoruba in the study location. 267 (96.4\%) have post-primary education, 17 (6.1\%) of which have postgraduate education; this may account for a high level of test comprehension and sophistication.

\subsection{Prevalence of Psychoactive Drug Use, Use of Un-Prescribed OTC medicines and Psychopathological Symptoms}

The prevalence of illicit substance usage and self-medication with OTC drugs among pregnant women was analyzed. As reported in Table 1, a total of $2.8 \%$ of the participants engage in the use of some sort of psychoactive substances, while $30 \%$ use non-prescribed over-the-counter drugs.

The patterns of the unprescribed use of OTC Drugs among the participants were analyzed and summarized in Table 2. The observed result shows an $18.1 \%$ prevalence for folic acid supplements use, $41.2 \%$ use of vitamin B supplements, $41.2 \%$ use of analgesics, $37.7 \%$ for blood tonic, $22.7 \%$ for Omega- 3 supplements; $34.7 \%$ for depressants (sleep-enhancing pills), 19.9\% for slimming tablets and teas, $22.7 \%$ for antidiarrheal, $25.3 \%$ for antibiotics use, and $24.2 \%$ for the alternative medication (Herbs). The total prevalence of non-prescribed use of over-the-counter drugs among the sample pregnant women is $30 \%$.

Table 3 displays the prevalence of psychopathological symptoms among

Table 1. Prevalence of psychoactive drug use and OTC drugs use among the participants.

\begin{tabular}{cc} 
Variables & Prevalence (\%) \\
\hline Psychoactive Substance Use & 2.8 \\
Unprescribed over-the-counter medications & 30 \\
\hline
\end{tabular}


Table 2. Patterns of unprescribed use of OTC drugs among the participants.

\begin{tabular}{lcc}
\hline \multicolumn{2}{c}{ Over-The-Counter Drugs } & Prevalence (\%) \\
\hline Food Supplements & Folic Acid & 18.1 \\
& Vitamin B Supplements & 41.2 \\
Blood Tonic & 37.7 \\
Omega 3 Supplements & 22.7 \\
Calcium & 29.6 \\
(Sleeping Pills) & 34.7 \\
Depressants $\quad$ Slimming Pills and Teas & 19.9 \\
$\quad$ Antidiarrheal & 22.7 \\
Analgesics & 41.2 \\
Antibiotics & 25.3 \\
Alternative Medicine (Herbs) & 24.2 \\
Total Prevalence of use of OTC drugs & 30.0 \\
\hline
\end{tabular}

Table 3. Prevalence of psychopathological symptoms.

\begin{tabular}{cc}
\hline Psychopathological Symptoms & Prevalence (\%) \\
\hline Insomnia & 39.7 \\
Intellectual Disorder & 36.1 \\
Heat Disorder & 22.0 \\
Mood Disorder & 31.4 \\
Head Region Disorder & 31.0 \\
Alimentary Tract Disorder & 28.9 \\
General Somatic Disorder & 39.7 \\
General Psychopathology & 31.8 \\
\hline
\end{tabular}

pregnant women sampled in this study. There was a $39.7 \%$ prevalence of insomnia, $36.1 \%$ prevalence of intellectual disorder, and a $22 \%$ prevalence of heat disorder among the participants. Further observed prevalence are; $31.4 \% \operatorname{mood}$ disorder, $31 \%$ head region disorder, $28.9 \%$ alimentary tract disorder, $39.7 \%$ general somatic disorder, and $31.8 \%$ general psychopathology.

\subsection{Test of Hypotheses}

We hypothesized that Self-Medication with OTC drugs would significantly predict levels of psychopathological symptoms among pregnant women in Osun State, southwestern Nigeria. Linear regression analyses were employed to test the degree to which Self-Medication independently and significantly predicted the severities of the symptoms as well as general psychopathology score among the participants. As summarized in Table 4, self-medication with OTC drugs was found to independently and significantly predict insomnia $(\beta=.178, p=.001)$, 
Table 4. Regression analysis of SM with OTC drugs on psychopathological symptoms among pregnant women.

\begin{tabular}{cccccccc}
\hline \multirow{2}{*}{$\begin{array}{c}\text { Psychopathological } \\
\text { Symptoms }\end{array}$} & $\mathrm{B}$ & $\boldsymbol{\beta}$ & $\mathrm{T}$ & $\mathrm{sig}$ & $\boldsymbol{R}^{2}$ & $\mathrm{~F}$ & $\boldsymbol{p}$ \\
\cline { 2 - 8 } & .051 & .178 & 3.31 & .001 & .178 & 10.97 & .001 \\
Insomnia & .042 & .244 & 4.60 & .000 & .244 & 21.00 & .000 \\
Intellect Disorder & .036 & .109 & 2.00 & .046 & .109 & 4.01 & .046 \\
Heat Disorder & .161 & .188 & 3.49 & .001 & .188 & 12.24 & .001 \\
Mood Disorder & 038 & .162 & 3.00 & .003 & .162 & 9.00 & .003 \\
Head Region Disorder & .045 & .118 & 2.18 & .030 & .118 & 4.76 & .030 \\
Alimentary Tract Disorder & .113 & .244 & 4.60 & .000 & .244 & 21.19 & .000 \\
General Somatic Disorder & .113 & .229 & & \\
General Psychopathology & .486 & .229 & 4.30 & .000 & .229 & 18.51 & .000 \\
\hline
\end{tabular}

reporting an $R^{2}$ of .178 , intellect disorder $(\beta=.244, p=.000)$ reporting an $R^{2}$ of .244, heat disorder $(\beta=.109, p=.046)$ reporting an $R^{2}$ of .046 , mood disorder $(\beta=.188, p=.001)$ reporting an $R^{2}$ of .188 , head region disorder $(\beta=.162, p$ $=.003)$ reporting an $R^{2}$ of .162 , alimentary tract disorder $(\beta=.118, p=.030)$ reporting an $R^{2}$ of .118 , General Somatic disorder $(\beta=.244, p=.000)$ reporting an $R^{2}$ of .244, and General psychopathology $(\beta=.229, p=.000)$ reporting an $R^{2}$ of .229.

This finding further reveals that $17.8 \% ; 24.4 \% ; 10.9 \%, 18.8 \%, 16.2 \%, 11.8 \%$, $24.4 \%$ and $22.9 \%$ variance in the severities of insomnia, intellect disorder, Heat disorder, mood disorder, head region disorder, alimentary tract disorder, general somatic disorder and general psychopathological symptoms respectively is explained by self-medication with OTC drugs by the participants.

\section{Discussion}

Our findings reveal a high prevalence rate of psychoactive drug use and the use of unprescribed OTC drugs among pregnant women. This finding supports the literature on drug use during pregnancy. For instance, an estimated range of 86\% (World Health Organization, 2020) to 90\% (Mosley, Smith, \& Dezan, 2015) of pregnant women take medications during pregnancy. This finding is a reflection of the rate of OTC and psychoactive drug usage among the general Nigerian population (Onisile, Akpunne, \& Alakija, 2020; Esan, Fasoro, Odesanya et al., 2018; Lawan, Abubakar, Jibo et al., 2013; Osemene \& Lamikanra, 2012; Fadare \& Tamuno, 2011), as well as from other countries (Wondesen, Satessa, \& Gelaw, 2016; El Ezz \& Ez-Elarab, 2011; Abay \& Amelo, 2010). According to Ayanwale, Okafor, and Odukoya (2017), one of the reasons for the high prevalence of self-medication with OTC is the cost-effectiveness, easy accessibility, perceptions that the problem as being too trivial to necessitate making an appointment with a healthcare professional, time-saving, and possibilities of people having few or no other options. 
This finding also supports Abduelmula and Mustafa (2017), who reported a $40 \%$ prevalence of OTC drug use among pregnant women in the United Arab Emirates (UAE). It is, however, noteworthy that there are possibilities of some medical complications' attendant with OTC on both mother and fetus. For instance, a study shows that high doses of acetylsalicylic acid could result in a high rate of perinatal mortality, low birth weight, prolonged labour, hemorrhage, and some form of congenital disabilities (Board, 2016).

Our study found that many pregnant women used food supplements (folic acid, vitamins, calcium, and so on). This is also similar to reported findings among UAE pregnant women (Abduelmula \& Mustafa, 2017), India (Inamdar, Aswa, Snokar et al., 2012) and Egypt (Hanafy, Sallam, Kharboush et al., 2016) and USA (Werler, Mitchell, Hernandez-Diaz, \& Honein, 2005). Studies show that food supplements have health benefits in pregnancy; for instance, Calcium supplements reduce preeclampsia and hypertension and maintaining a healthy heart for both fetus and mother (WHO, 2013). Iron intake help to fight depression and build resistance to stress and disease in the mother as well as being an essential part of the red blood cells as mothers have an increased maternal red blood mass (Clevelandclinic, 2016). However, the United States Food and Drug Administration (FDA) categorized some drugs as having evidence of fetal risk (Atmadani, Nkoka, Yunita et al., 2020; Yang, Walker, Krewski, Yang, Nimrod, Garner et al., 2008). Low iron levels have been linked with premature delivery, low birth weight, and infant mortality (Centrum.ca, 2016). One of the side effects of analgesics (paracetamol) during pregnancy is neurological developmental disorder (psychomotor, behavioural, and temperamental outcomes for the child) (Brandlistuen, Ystrom, Nulman, Koren, \& Nordeng, 2013). Thus, pregnant women need to be better advised by pharmacists, doctors, and other health care providers on the risk factor of OTC drug usage.

This study also reported a high prevalence of psychopathological symptoms among pregnant women. This might be due to the view of pregnancy as associated with psychological changes and challenges (Amiel Castro, Pinard Anderman, Glover et al., 2017). It is, therefore, not unusual to experience some form of psychological distresses during pregnancy (Ross \& McLean, 2006). It is worthy of note that regular psychological changes are different from psychopathological symptoms and psychological disorders that are measured in this study. These findings of our study are consistent with previous literature; for instance, a Swedish study returned a $14 \%$ psychiatric disorder among pregnant women (Signal, Paine, Sweeney et al., 2017). A similar high prevalence of antenatal anxiety and depression has been reported in Bangladesh (Nasreen, Kabir, Forsell et al., 2011), Pakistan (Karmaliani, Asad, Bann et al., 2009) Saudi Arabia (Alqahtani, Al Khedair, Al-Jeheiman et al., 2018), and Oman (Al-Azri, Al-Lawati, Al-Kamyani et al., 2016). A similar high prevalence of psychopathological symptoms among pregnant women has been reported in Western climes (Gawlik, Waldeier, Müller et al., 2013; Peñacoba-Puente, Carmona-Monge, Marin-Morales et al., 2013; Thiagayson, Krishnaswamy, Lim et al., 2013). It is normal for a pregnant 
woman to be anxious and stressed. Studies show that one in five women have mental health issues during pregnancy or after childbirth (Center for Behavioral Health Statistics and Quality, 2017; Howard, Molyneaux, Dennis, Rochat, Stein, \& Milgrom, 2014; Minichino, Bersani, Calò et al., 2013). Thoughts of possible changes in role, whether or not parenting the child would be done right, fear of possible problems with the pregnancy or the child, fear of childbirth, perceived social support, and so on, can engendering mental health issues during pregnancy.

Finally, we found that self-medication with OTC significantly predicted severities of Insomnia, Intellect disorder, Heat disorder, Mood disorder, Head region disorder, Alimentary tract disorder, General somatic disorder, and General psychopathological symptoms among the antenatal patients. However, this finding did not observe whether it was the self-medication that led to the observed psychopathological symptoms of vice-versa. One specific thing is, however, consistent with literature, (Onisile, Akpunne, \& Alakija, 2020; Howard, Ryan, Trevillion, Anderson, Bick, Bye et al., 2018; Jones, Chandra, Dazzan, \& Howard, 2014), we observed a strong link between OTC self-medication and manifested psychopathological symptoms among the population. Literature shows that individuals with mild, subclinical, and severe mental health disorders may self-medicate with some form of OTC drugs and use some psychoactive substances (Santucci, 2012; Goldstein \& Bukstein, 2010).

\section{Conclusion and Recommendations}

It can be concluded that there is a high prevalence of self-medication with OTC drugs among Nigerian pregnant women. Also, self-medication with OTC drugs is a significant predictor of psychopathological symptoms among the participants. Due to the high prevalence of psychoactive substance abuse and self-medication of OTC drugs as reported among participants, the study recommends periodic screening using standard psychological screening tests combined with routine psychoeducation on appropriate medication usage in pregnancy.

Furthermore, the mass media should be utilized to educate pregnant women on the ills of self-medication in pregnancy and its effect on psychological health, and the Nigerian government should endeavor to enforce drug control policies.

Moreover, this study could be replicated among pregnant women who do not have access to antenatal care services and non-pregnant women. Also, other variables such as domestic violence, sexual dissatisfaction, personality, self-esteem as well as socio-demographic variables which are capable of predicting levels of psychological health can also be assessed. Also, longitudinal studies may be conducted to identify the implications of self-medication during pregnancy on children's post-birth.

\section{Ethical Considerations}

This study focused on humans as elements of the investigation. As a result, the 
ethics of research for human subjects were observed. The researcher obtained a certificate for reviewing regulatory and informational documents on human-subject protection, passing a quiz on the responsible conduct of human studies, and signing a statement of commitment on the protection of the rights and welfare of human subjects participating in research after undergoing the Nigerian National Code of Health Research Ethics of Center of Bioethics and Research, Nigeria and the University of Miami, Florida online Course. Additionally, the research purpose and methodology were subjected to scrutiny by the Internal Research Ethics Committee of Redeemer's University, Ede, Osun State, and was given due approval. Full approval to administer research instruments to pregnant women registered with and attending antenatal care clinic at the State Specialist Hospital, Asubiaro, Osogbo, Osun State was obtained from the Specialist Hospital Osogbo Health Research Ethics Committee (SHOREC) after a full committee review. In administering the research instruments, respondents were also duly informed about the research topic, and no coercion was used. All respondents remain anonymous.

\section{Limitation}

Self-reported OTC and psychoactive drug use, non-inclusion of pregnant women who are not using any antenatal facility, and non-pregnant women are some limitations of this study. Also, the research was carried out in one out of six geopolitical regions in Nigeria, thus placing a caution on the generalizability of the findings.

\section{Conflicts of Interest}

The authors declare no conflicts of interest regarding the publication of this paper.

\section{References}

Abay, S. M., \& Amelo, W. (2010). Assessment of Self-Medication Practices among Medical, Pharmacy, and Health Science Students in Gondar University, Ethiopia. Journal of Young Pharmacists, 2, 306-310. https://doi.org/10.4103/0975-1483.66798

Abduelmula, R., \& Abduelkarem, H. M. (2017). Use of Over-the-Counter Medication among Pregnant Women in Sharjah, United Arab Emirates. Journal of Pregnancy, 2017, Article ID: 4503793. https://doi.org/10.1155/2017/4503793

Abula, T., \& Worku, A. (2001). Self-Medication in Three Towns of North-West Ethiopia. The Ethiopian Journal of Health Development, 15, 25-30. https://doi.org/10.4314/ejhd.v15i1.9893

Afolabi, A. (2009). Factors Influencing the Pattern of Self-Medication in an Adult Nigerian Population. Annals of African Medicine, 7, 120-127. https://doi.org/10.4103/1596-3519.55666

Akinnawo, E., \& Oforwe, C. (2012). A Validation Study of API-Form X on Nigerian Adolescents. IFE PsychologIA, 20, 41.

Al-Azri, M., Al-Lawati, I., Al-Kamyani, R. et al. (2016). Prevalence and Risk Factors of Antenatal Depression among Omani Women in a Primary Care Setting: Cross-Sectional 
Study. Sultan Qaboos University Medical Journal, 16, e35-e41. https://doi.org/10.18295/squmj.2016.16.01.007

Almasdy, D., \& Sharrif, A. (2011). Self-Medication Practice with Nonprescription Medication among University Students: A Review of the Literature. Archives of Pharmacy Practice, 2, 95-100.

Alqahtani, A. H., Al Khedair, K., Al-Jeheiman, R. et al. (2018). Anxiety and Depression during Pregnancy in Women Attending Clinics in a University Hospital in Eastern Province of Saudi Arabia: Prevalence and Associated Factors. International Journal of Women's Health, 10, 101-108. https://doi.org/10.2147/IJWH.S153273

Ameh, S., Adeleye, O. A., Kabiru, C. W. et al. (2016). Predictors of Poor Pregnancy Outcomes among Antenatal Care Attendees in Primary Health Care Facilities in Cross River State, Nigeria: A Multilevel Model. Maternal and Child Health Journal, 20, 1662-1672. https://doi.org/10.1007/s10995-016-1965-5

Amiel Castro, R. T., Pinard Anderman, C., Glover, V., O’Connor, T. G., Ehlert, U., \& Kammerer, M. (2017). Associated Symptoms of Depression: Patterns of Change during Pregnancy. Archives of Women's Mental Health, 20, 123-128. https://doi.org/10.1007/s00737-016-0685-6

Angamo, M. T., \& Wabe, N. T. (2012). Knowledge, Attitude, and Practice of Self-Medication in Southwest Ethiopia. International Journal of Pharmaceutical Sciences and Research, 3, 1005-1010.

Atmadani, R. N., Nkoka, O., Yunita, S. L. et al. (2020). Self-Medication and Knowledge among Pregnant Women Attending Primary Healthcare Services in Malang, Indonesia: A Cross-Sectional Study. BMC Pregnancy Childbirth, 20, Article No. 42. https://doi.org/10.1186/s12884-020-2736-2

Avalew, M. B. (2017). Self-Medication Practice in Ethiopia: A Systematic Review. Patient Prefer Adherence, 11, 401-413. https://doi.org/10.2147/PPA.S131496

Awaritefe, A. (1982). The Awaritefe Psychological Index. Nigerian Journal of Clinical Psychology, 1, 45-51.

Ayanwale, M. B., Okafor, I. P., \& Odukoya, O. O. (2017). Self-Medication among Rural Residents in Lagos, Nigeria. Journal of Tropical Medicine, 19, 65-71. https://doi.org/10.4103/jomt.jomt_51_16

Bennadi, D. (2014). Self-Medication: A Current Challenge. Journal of Basic and Clinical Pharmacy, 5, 19-23. https://doi.org/10.4103/0976-0105.128253

Board, BMA (2016). Buying Pregnancy Multivitamins: Baby Center. https://www.babycentre.co.uk/a561818/buying-pregnancy-multivitamins

Brandlistuen, R. E., Ystrom, E., Nulman, I., Koren, G., \& Nordeng, H. (2013). Prenatal Paracetamol Exposure and Child Neurodevelopment: A Sibling-Controlled Cohort Study. International Journal of Epidemiology, 42, 1702-1713. https://doi.org/10.1093/ije/dyt183

Buck, M. (2007). Self-Medication by Adolescents. Journal of Pediatric Pharmacy, 13, 1-4.

Center for Behavioral Health Statistics and Quality (2017). Results from the 2016 National Survey on Drug Use and Health: Detailed Tables. Rockville, MD: Substance Abuse and Mental Health Services Administration.

Centrum.ca (2016). Are You Getting Enough Iron? WebMD. http://www.webmd.com/baby/areyou-getting-enough-iron

Chang, F. R., \& Trivedi, P. K. (2003). Economics of Self-Medication: Theory and Evidence. Health Economics, 12, 721 739. https://doi.org/10.1002/hec.841

Clevelandclinic (2016). Your Guide to a Healthy Pregnancy. Ob/Gyn \& Women's Health 
Institute. http://www.clevelandclinic.org/healthinfo/pdfv2/pdfs/15646.pdf

Czeizel, A. E., Gidai, J., Petik, D. et al. (2008). Self-Poisoning during Pregnancy as a Model for Teratogenic Risk Estimation of Drugs. Toxicology and Industrial Health, 24, 11-28. https://doi.org/10.1177/0748233708089020

Dellicour, S., ter Kuile, F. O., \& Stergachis, A. (2008). Pregnancy Exposure Registries for Assessing Antimalarial Drug Safety in Pregnancy in Malaria-Endemic Countries. PLOS Medicine, 5, e187. https://doi.org/10.1371/journal.pmed.0050187

El Ezz, N. F., \& Ez-Elarab, H. S. (2011). Knowledge, Attitude and Practice of Medical Students towards Self Medication at Ain Shams University, Egypt. Journal of Preventive Medicine and Hygiene, 52, 196-200.

Esan, D. T., Fasoro, A. A., Odesanya, O. E. et al. (2018). Assessment of Self-Medication Practices and its Associated Factors among Undergraduates of a Private University in Nigeria. Journal of Environmental and Public Health, 2018, Article ID: 5439079. https://doi.org/10.1155/2018/5439079

Eticha, T., \& Mesfin, K. (2014). Self-Medication Practices in Mekelle, Ethiopia. PLoS ONE, 9, e97464. https://doi.org/10.1371/journal.pone.0097464

Fadare, J. O., \& Tamuno, I. (2011). Antibiotic Self-Medication among University Medical Undergraduates in Northern Nigeria. Journal of Public Health and Epidemiology, 3, 217-220.

Fantel, A. G., Shepard, T. H., Newell-Morris, L. L. et al. (1977). Teratogenic Effects of Retinoic Acid in Pigtail Monkeys (Macaca Nemestrina) I. General Features. Teratology, 15, 65-71. https://doi.org/10.1002/tera.1420150109

Garofalo, L., Di Giuseppe, G., \& Angelillo, I. F. (2015). Self-Medication Practices among Parents in Italy. BioMed Research International, 2015, Article ID: 580650. https://doi.org/10.1155/2015/580650

Gawlik, S., Waldeier, L., Müller, M. et al. (2013). Subclinical Depressive Symptoms during Pregnancy and Birth Outcome-A Pilot Study in a Healthy German Sample. Archives of Women's Mental Health, 16, 93-100. https://doi.org/10.1007/s00737-012-0320-0

Gbagbo, F. Y., \& Nkrumah, J. (2020). Implications of Self-Medication in Pregnancy for Safe Motherhood and Sustainable Development Goal-3 in Selected Ghanaian Communities. Public Health in Practice, 1, Article ID: 100017. https://doi.org/10.1016/j.puhip.2020.100017

Gebreegziabher, T. L., Berhe, D. F., Gutema, G. B., \& Kabtyimer, B. N. (2012). Drug Utilization Pattern and Potential Teratogenesity Risk among Pregnant Women; the Case of Ayder Referral Hospital, Tigray Ethiopia. International Journal of Pharmaceutical Sciences and Research, 3, 137.

Goldstein, B. I., \& Bukstein, O. G. (2010). Comorbid Substance Use Disorders among Youth with Bipolar Disorder: Opportunities for Early Identification and Prevention. Journal of Clinical Psychiatry, 71, 348-358. https://doi.org/10.4088/JCP.09r05222gry

Gutema, G. B., Gadisa, D. A., Kidanemariam, Z. A. et al. (2011). Self-Medication Practices among Health Sciences Students: The Case of Mekelle University. Journal of Applied Pharmaceutical Science, 1, 183-189.

Hanafy, A. S., Sallam, A. S., Kharboush, F. I. et al. (2016). Drug Utilization Pattern during Pregnancy in Alexandria, Egypt. European Journal of Pharmaceutical and Medical Research, 3, 19-29.

Howard, L. M., Molyneaux, E., Dennis, C. L., Rochat, T., Stein, A., \& Milgrom, J. (2014). Non-Psychotic Mental Disorders in the Perinatal Period. The Lancet, 384, 1775-1788. https://doi.org/10.1016/S0140-6736(14)61276-9 
Howard, L. M., Ryan, E. G., Trevillion, K., Anderson, F., Bick, D., Bye, A. et al. (2018). Accuracy of the Whooley Questions and the Edinburgh Postnatal Depression Scale in Identifying Depression and Other Mental Disorders in Early Pregnancy. The British Journal of Psychiatry, 212, 50-56. https://doi.org/10.1192/bjp.2017.9

Hughes, C. M., McElnay, J. C., \& Fleming, G. F. (2001). Benefits and Risks of Self-Medication. Drug Safety, 24, 1027-1037. https://doi.org/10.2165/00002018-200124140-00002

Inamdar, I. F., Aswa, N. R., Snokar, V. K. et al. (2012). Drug Utilization Pattern during Pregnancy. Indian Medical Gazette, 146, 305-311.

Jalilian, F., Hazavehei, S. M., Vahidinia, A. A. et al. (2017). Prevalence and Related Factors for Choosing Self Medication among Pharmacies Visitors Based on Health Belief Model in Hamadan Province, West of Iran. Journal of Research in Health Sciences, 13, 81-85.

Jones, I., Chandra, P. S., Dazzan, P., \& Howard, L. M. (2014). Bipolar Disorder, Affective Psychosis, and Schizophrenia in Pregnancy and the Post-Partum Period. The Lancet, 384, 1789-1799. https://doi.org/10.1016/S0140-6736(14)61278-2

Kamat, V. R., \& Nichter, M. (1998). Pharmacies, Self-Medication and Pharmaceutical Marketing in Bombay, India. Social Science \& Medicine, 47, 779-794.

https://doi.org/10.1016/S0277-9536(98)00134-8

Karimy, M., Rezaee-Momtaz, M., Tavousi, M. et al. (2019). Risk Factors Associated with Self-Medication among Women in Iran. BMC Public Health, 19, 1033. https://doi.org/10.1186/s12889-019-7302-3

Karmaliani, R., Asad, N., Bann, C. M. et al. (2009). Prevalence of Anxiety, Depression, and Associated Factors among Pregnant Women of Hyderabad, Pakistan. International Journal of Social Psychiatry, 55, 414-424. https://doi.org/10.1177/0020764008094645

Khan, R. A. (2011). Self-Medication with Antibiotics: Practices among Pakistani Students in Sweden and Finland. Huddinge: Södertörns University.

Lacroix, I., Damase-Michel, C., Lapeyre-Mestre, M. et al. (2000). Prescription of Drugs during Pregnancy in France. The Lancet, 356, 1735-1736.

https://doi.org/10.1016/S0140-6736(00)03209-8

Lawan, U. M., Abubakar, I. S., Jibo, A. M. et al. (2013). Pattern, Awareness and Perceptions of Health Hazards Associated with Self-Medication among Adult Residents of Kano Metropolis, North-Western Nigeria. Indian Journal of Community Medicine, 38, 144-151. https://doi.org/10.4103/0970-0218.116350

Leung, H. Y., Saini, B., \& Ritchie, H. E. (2018). Medications and Pregnancy: The Role of Community Pharmacists-A Descriptive Study. PLoS ONE, 13, e0195101. https://doi.org/10.1371/journal.pone.0195101

Mihretie, T. M. (2014). Self-Medication Practices with Antibiotics among Urban Dwellers of Bahir Dar Town, North West Ethiopia. Addis Ababa: Addis Ababa University.

Minichino, A., Bersani, F. S., Calò, W. K. et al. (2013). Smoking Behaviour and Mental Health Disorders-Mutual Influences and Implications for Therapy. International Journal of Environmental Research and Public Health, 10, 4790-4811.

https://doi.org/10.3390/ijerph10104790

Mitchell, A. A. (2002). Special Considerations in Studies of Drug-Induced Birth Defects. In B. L. Strom (Ed.), Pharmacoepidemiology (3rd ed., pp. 749-763). Chichester: John Wiley \& Sons. https://doi.org/10.1002/0470842555.ch42

Mosley, J. F., Smith, L. L., \& Dezan, M. D. (2015). An Overview of Upcoming Changes in Pregnancy and Lactation Labeling Information. Pharmacy Practice, 13, 605.

https://doi.org/10.18549/PharmPract.2015.02.605 
Mossa, D. A., Wabe, N. T., \& Angamo, M. T. (2012). Self-Medication with Antibiotics and Antimalarials in the Community of Silte Zone, South Ethiopia. Türk Silahlı Kuvvetleri Koruyucu Hekimlik Bülteni, 11, 529-536.

https://doi.org/10.5455/pmb.1-1314892446

Nasreen, H. E., Kabir, Z. N., Forsell, Y. et al. (2011). Prevalence and Associated Factors of Depressive and Anxiety Symptoms during Pregnancy: A Population-Based Study in Rural Bangladesh. BMC Womens Health, 11, 22.

https://doi.org/10.1186/1472-6874-11-22

Olugbenga-Bello, A., Adebimpe, W., Osundina, F., \& Abdulsalam (2013). Perception on Prevention of Mother to Child-Transmission (Pmtct) of HIV among Women of Reproductive Age Group in Osogbo, Southwestern Nigeria. https://doi.org/10.2147/IJWH.S45815

Omoluabi, P. F. (1995). A Review of the Incidence of Nonprescription Psychoactive Substance Use/Misuse in Nigeria. The International Journal of the Addictions, 30, 445-458. https://doi.org/10.3109/10826089509048736

Onisile, D. O., Akpunne, B. C., \& Alakija, O. A. (2020). Psychoactive Substance and Psychopathological Symptoms among Nigerian Secondary Schools Adolescents. International Neuropsychiatric Disease Journal, 13, 1-10. https://doi.org/10.9734/indj/2019/v13i3-430114

Osemene, K. P., \& Lamikanra, A. (2012). A Study of the Prevalence of Self-Medication Practice among University Students in South-Western Nigeria. Tropical Journal of Pharmaceutical Research, 11, 683-689. https://doi.org/10.4314/tjpr.v11i4.21

Peñacoba-Puente, C., Carmona-Monge, F. J., Marin-Morales, D. et al. (2013). Coping Strategies of Spanish Pregnant Women and Their Impact on Anxiety and Depression. Research in Nursing \& Health, 36, 54-64. https://doi.org/10.1002/nur.21513

Ravindu, G., \& Avinash, S. P. (2018). Drug Use during Pregnancy. MSD Manual, Consumer Version.

https://www.msdmanuals.com/home/women-s-health-issues/drug-use-during-pregnan cy/drug-use-during-pregnancy

Roser, M., \& Ritchie, H. (2013). Maternal Mortality. https://ourworldindata.org/maternal-mortality

Ross, L., \& McLean, M. (2006). Anxiety Disorders during Pregnancy and the Postpartum Period. A Systematic Review. The Journal of Clinical Psychiatry, 67, 1285-1298. https://doi.org/10.4088/JCP.v67n0818

Ruiz, M. E. (2007). Risks of Self-Medication Practices. Current Drug Safety, 5, 315-323. https://doi.org/10.2174/157488610792245966

Santucci, K. (2012). Psychiatric Disease and Drug Abuse. Current Opinion in Pediatrics, 24, 233-237. https://doi.org/10.1097/MOP.0b013e3283504fbf

Schwarz, U., Buschel, B., \& Kirch, W. (2008). Unwanted Pregnancy on Self-Medication with St John's Wort Despite Hormonal Contraception. British Journal of Clinical Pharmacology, 55, 112-113. https://doi.org/10.1046/j.1365-2125.2003.01716.x

Shankar, P., Partha, P., \& Shenoy, N. (2002). Self-Medication and Non-Doctor Prescription Practices in Pokhara Valley, Western Nepal: A Questionnaire-Based Study. BMC Family Practice, 3, 17. https://doi.org/10.1186/1471-2296-3-17

Signal, T. L., Paine, S. J, Sweeney, B. et al. (2017). The Prevalence of Symptoms of Depression and Anxiety, and the Level of Life Stress and Worry in New Zealand Mãori and Non-Māori Women in Late Pregnancy. Australian and New Zealand Journal of Psychiatry, 51, 168-176. https://doi.org/10.1177/0004867415622406

Sleath, B., Rubin, R. H., Campbell et al. (2001). Physician-Patient Communication about 
Over-the-Counter Medications. Social Science \& Medicine, 53, 357-369. https://doi.org/10.1016/S0277-9536(00)00341-5

Suleman, S., Ketsela, A., \& Mekonnen, Z. (2009). Assessment of Self-Medication Practices in Assendabo Town, Jimma Zone, South-Western Ethiopia. Research in Social and Administrative Pharmacy, 5, 76-81. https://doi.org/10.1016/j.sapharm.2008.04.002

Thiagayson, P., Krishnaswamy, G., Lim, M. L. et al. (2013). Depression and Anxiety in Singaporean High-Risk Pregnancies: Prevalence and Screening. General Hospital Psychiatry, 35, 112-116. https://doi.org/10.1016/j.genhosppsych.2012.11.006

Ward, S. A., Sevene, E. J., Hastings, I. M. et al. (2007). Antimalarial Drugs and Pregnancy: Safety, Pharmacokinetics, and Pharmacovigilance. The Lancet Infectious Diseases, 7, 136-144. https://doi.org/10.1016/S1473-3099(07)70025-7

Werler, M. M., Mitchell, A. A., Hernandez-Diaz, S., \& Honein, M. A. (2005). Use of Over-the-Counter Medications during Pregnancy. American Journal of Obstetrics and Gynecology, 193, 771-777. https://doi.org/10.1016/j.ajog.2005.02.100

WHO World Health Organization (2013). WHO Guideline: Calcium Supplementation in Pregnant Women. http://apps.who.int/iris/bitstream/10665/85120/1/9789241505376_eng.pdf

WHO World Health Organization (2020). Safety of Medicines in Pregnancy: General Principles.

https://www.who.int/reproductivehealth/publications/maternal_perinatal_health/clinic $\underline{\mathrm{al} / \mathrm{en} /}$

Wondesen, A., Satessa, G., \& Gelaw, B. (2016). Drug Use Pattern among Pregnant Women in Adama Hospital Medical College, South East Shewa, Ethiopia. International Journal of Pharma Sciences, 6, 1426-1435.

Wood, A. J., Koren, G., Pastuszak, A. et al. (1998). Drugs in Pregnancy. The New England Journal of Medicine, 338, 1128-1137. https://doi.org/10.1056/NEJM199804163381607

World Health Organization (1998)!. The Role of the Pharmacist in Self-Care and Self-Medication: Report of the 4th WHO Consultative Group on the Role of the Pharmacist, The Hague, The Netherlands, 26-28 August 1998. World Health Organization. https://apps.who.int/iris/handle/10665/65860

Yang, T., Walker, M. C., Krewski, D., Yang, Q., Nimrod, C., Garner, P. et al. (2008). Maternal Characteristics Associated with Pregnancy Exposure to FDA Category C, D, and $\mathrm{X}$ Drugs in a Canadian Population. Pharmacoepidemiology and Drug Safety, 17, 270-277. https://doi.org/10.1002/pds.1538 